\title{
To fill or not to fill: a qualitative cross- country study on dentists' decisions in managing non-cavitated proximal caries lesions
}

\author{
F. Schwendicke $1^{*}$, L. A. Foster Page ${ }^{2}$, L. A. Smith², M. Fontana ${ }^{3}$, W. M. Thomson² and S. R. Baker ${ }^{4}$
}

\begin{abstract}
Background: This study aimed to identify barriers and enablers for dentists managing non-cavitated proximal caries lesions using non- or micro-invasive (NI/MI) approaches rather than invasive and restorative methods in New Zealand, Germany and the USA.

Methods: Semi-structured interviews were conducted, focusing on non-cavitated proximal caries lesions (radiographically confined to enamel or the outer dentine). Twelve dentists from New Zealand, 12 from Germany and 20 from the state of Michigan (USA) were interviewed. Convenience and snowball sampling were used for participant recruitment. A diverse sample of dentists was recruited. Interviews were conducted by telephone, using an interview schedule based on the Theoretical Domains Framework (TDF).

Results: The following barriers to managing lesions non- or micro-invasively were identified: patients' lacking adherence to oral hygiene instructions or high-caries risk, financial pressures and a lack of reimbursement for NI/MI, unsupportive colleagues and practice leaders, not undertaking professional development and basing treatment on what had been learned during training, and a sense of anticipated regret (anxiety about not restoring a proximal lesion in its early stages before it progressed). The following enablers were identified: the professional belief that remineralisation can occur in early non-cavitated proximal lesions and that these lesions can be arrested, the understanding that placing restorations weakens the tooth and inflicts a cycle of re-restoration, having up-to-date information and supportive colleagues and work environments, working as part of a team of competent and skilled dental practitioners who perform NI/MI (such as cleaning or scaling), having the necessary resources, undertaking ongoing professional development and continued education, maintaining membership of professional groups and a sense of professional and personal satisfaction from working in the patient's best interest. Financial aspects were more commonly mentioned by the German and American participants, while continuing education was more of a focus for the New Zealand participants.
\end{abstract}

Conclusions: Decisions on managing non-cavitated proximal lesions were influenced by numerous factors, some of which could be targeted by interventions for implementing evidence-based management strategies in practice.

Keywords: Attitudes, Dental, Decision-making, Enamel caries, Evidence-based practice, Qualitative studies, Theoretical Domains Framework

\footnotetext{
* Correspondence: falk.schwendicke@charite.de

'Department for Operative and Preventive Dentistry, Charité -

Universitätsmedizin Berlin, Freie Universität Berlin, Humboldt-Universität zu

Berlin, and Berlin Institute of Health, Aßmannshauser Str. 4-6, 14197 Berlin,

Germany

Full list of author information is available at the end of the article
} 


\section{Background}

Dental caries is highly prevalent and costly to treat [1, 2]. Traditionally, caries has been treated by the surgical removal of all carious tissue from the tooth and the placement of a restoration in the resulting cavity. Contemporary management aims to control disease activity non-invasively (NI), without breaching the surface of the tooth (by restricting cariogenic sugars intake, avoiding biofilm maturation or remineralising) [3-5]. Alternatively, micro-invasive (MI) therapies can be applied, with only a few micrometres of tooth tissue being removed, usually during a conditioning step (using acid). Sealing caries lesions or infiltrating them using resins are such micro-invasive therapies. They impede bacterial acid diffusion into the tooth tissues, arresting the lesion [6].

NI/MI control caries lesions without placing restorations $[4,7]$ and are currently recommended for managing early, non-cavitated caries lesions [6, 8-10]. However, dentists have not unequivocally adopted NI/ MI [11]; instead, most continue to intervene invasively even for non-cavitated lesions [12-14]. To understand how factors such as knowledge, skills, attitudes or behaviours shape dentists' decision-making, qualitative studies are needed; those could then inform interventions to promote evidence-based management for noncavitated caries lesions [15]. Such studies should use theoretical frameworks [16].

Here, we used the Theoretical Domains Framework (TDF), which has been used previously to understand the motivations, cognitions and behaviours of health professionals when implementing evidence-based practice [17-19]. Few dental studies have used it [17, 20, 21]. Since interventions for implementing behaviour change must be setting-specific, we aimed to identify barriers and enablers to dentists non- or micro-invasively managing proximal caries lesions in New Zealand (NZ), the USA, and Germany. These countries were chosen for pragmatic reasons but were well suited to contrast barriers and enablers in three different dental healthcare systems.

\section{Methods}

Semi-structured interviews covered seven areas: (1) the dentist's background (e.g. years of experience), (2) current clinical practice and decision-making for $\mathrm{NI} / \mathrm{MI} /$ restoration, (3) knowledge and skills (e.g. awareness of guidelines), (4) professional role and identity (e.g. whose responsibility is NI/MI), (5) goals (e.g. changes to routine management in the future), (6) beliefs about consequences (e.g. benefits/disadvantages of NI/MI), (7) environmental context (e.g. factors that influence NI/MI), and (8) social influences (e.g. patient choice) (Additional file 1 for interview schedule). Our reporting follows the COREQ checklist [22]. Ethical approval was obtained (see "Ethics approval and consent to participate" section).

\section{Research team and reflexivity}

An experienced psychologist and qualitative researcher (SB) led the design of the interview schedule and data analysis. The clinical and dental research expertise was led by three researchers, one from each country (FS, LFP, MF). All researchers (a health psychologist, two cariologists, a dental public health specialist and a sociologist) acted as an expert panel to determine how to apply the TDF to oral healthcare [17]. Interviews were conducted by three dental researchers with a previous experience or trained via pilot interviews (see below). Those were conducted in the second half of 2016, in order to assess interview schedule suitability and provide feedback to interviewers. A dental researcher with a previous experience in qualitative research (LS) coded the interviews; $10 \%$ were additionally and independently coded by SB. The interviewees did not have any relationship with the interviewers; all were informed about the study's purpose before consenting.

\section{Theoretical framework and methodology}

Providing the underlying structure for data collection, analysis and interpretation, the TDF comprises 14 theoretical domains, each having a number of different constructs [23]. Ten of the 14 TDF domains were utilised in this study (Table 1) because these were felt by the expert panel to be the most relevant.

\section{Participant selection}

NZ, the USA and Germany were chosen primarily for pragmatic reasons, including research team location and cost minimisation; they also represented three very different dental healthcare systems. In the USA, we sampled from only one state (Michigan) because it was felt that it would not be possible to use a USA-wide sample of dentists. We chose accordingly to sample from a state with many of the public and private healthcare systems available throughout the country. In each country, lists of registered dentists supplied names of general dentists who were then informed about the study by the research assistant or assistant research fellow in that country via email or telephone. Informal approaches and snowballing were also used.

Although there is no specific requirement for the number of participants in qualitative research [24], we wanted to gather a diverse range of general dentists (by gender, age, time since graduation, type of practice, rural/urban) and collect sufficiently broad data to understand barriers and enablers within each country. We continued recruiting in each country until no new data or no new patterns or themes emerged [25]. Our final sample comprised 44 participants (12 in NZ, 12 in Germany, 20 in the USA; Table 2). The characteristics of 
Table 1 Domains of the Theoretical Domains Framework (TDF)

\begin{tabular}{|c|c|c|}
\hline Domain & Construct & Definition \\
\hline \multirow[t]{3}{*}{ Knowledge } & Knowledge & Knowledge of a condition or scientific rationale. \\
\hline & Procedural knowledge & Knowing how to do something. \\
\hline & $\begin{array}{l}\text { Knowledge of task } \\
\text { environment }\end{array}$ & Knowledge of the social and material context in which a task is undertaken. \\
\hline \multirow[t]{6}{*}{ Skills } & Skills & An ability or proficiency acquired through practice. \\
\hline & Skills development & $\begin{array}{l}\text { The gradual acquisition or advancement through progressive stages of an ability or proficiency } \\
\text { acquired through training and practice. }\end{array}$ \\
\hline & Competence & One's repertoire of skills and ability especially as it is applied to a task or set of tasks. \\
\hline & Ability & $\begin{array}{l}\text { Competence or capacity to perform a physical or mental act. Ability may be either learned or } \\
\text { unlearned. }\end{array}$ \\
\hline & Interpersonal skills & $\begin{array}{l}\text { An aptitude enabling a person to carry on effective relationships with others, such as ability to } \\
\text { cooperate, to assume appropriate relationships with others or to exhibit adequate flexibility. }\end{array}$ \\
\hline & Practice & $\begin{array}{l}\text { Repetition of an act, behaviour or series of activities, often to improve performance or acquire } \\
\text { a skill. }\end{array}$ \\
\hline \multirow[t]{6}{*}{ Social influences } & Social pressure & The exertion of influence on a person or person or group by another person or group. \\
\hline & Social norms & $\begin{array}{l}\text { Socially determined consensual standards that indicate what behaviours are considered typical in } \\
\text { a given context and what behaviours are considered proper in the context. }\end{array}$ \\
\hline & Group conformity & The act of consciously maintaining a certain degree of similarity to those in your general social circle. \\
\hline & Social comparisons & The process by which people evaluate their attitudes, abilities, or performance relative to others. \\
\hline & Group norms & Any behaviour, belief, attitude or emotion reaction held to be correct by any given group in society. \\
\hline & Social support & $\begin{array}{l}\text { The apperception or provision of assistance or comfort to others, typically in order to help them } \\
\text { to cope with a variety of biological, psychological or social stressors. Support may arise from } \\
\text { interpersonal relationships in an individual's social network, involving friends, neighbours, religious } \\
\text { institutions, colleagues, caregivers or support groups. }\end{array}$ \\
\hline
\end{tabular}

Power The capacity to influence others, even when they try to resist this influence.

Intergroup conflict Disagreement or confrontation between two or more groups and their members. This may involve physical violence, interpersonal discord, or psychological tension.

Alienation Estrangement from one's social group; a deep seated sense of dissatisfaction with one's personal experiences that can be a source of lack of trust in one's social or physical environment or in oneself; the feeling of separation between one's thoughts and feelings.

Group identity The set of behaviour or personal characteristics by which an individual is recognisable (and portrays) as a member of a group.

Modelling In developmental psychology, the process by which one or more individuals or other entities serve as examples (models) that a child will copy.

Social/ professional Professional identity role and identity
Beliefs about consequences
The characteristics by which an individual is recognised relating to, or connected with, or benefitting, a particular profession.

Professional role

Social identity

Identity

The behaviour considered appropriate for a particular kind of work or social position.

The set of behaviours or personal characteristics by which an individual is recognisable [and portrays] as a member of a social group, relating to, or connected with or benefitting a particular profession

An individual's sense of self defined by (a) a set of physical and psychological characteristics that is not wholly shared with any other person and (b) a range of social and interpersonal affiliations (e.g. social roles).

Professional boundaries The bounds or limits relating to, or connected with, a particular profession or calling.

Professional confidence An individual's beliefs in his or her repertoire of skills and ability as it is applied to tasks or set of tasks.

Group identity The set of behaviours or personal characteristics by which an individual is recognisable [and portrays] as a member of a group.

Leadership

The process involved in leading others, including organising directing, coordinating and motivating their efforts toward achievement of certain group or organisational goals.

Beliefs

The thing one believed in, the proposition or set of propositions held true. 
Table 1 Domains of the Theoretical Domains Framework (TDF) (Continued)

\begin{tabular}{ll} 
Domain Construct & Definition \\
\hline & $\begin{array}{l}\text { Cognitive, emotional, behavioural and affective outcomes that are assumed to be associated with } \\
\text { future or intended behaviours. These assumed outcomes can either promote or inhibit future } \\
\text { behaviour. }\end{array}$ \\
$\begin{array}{ll}\text { Characteristics of } \\
\text { outcome expectancies }\end{array}$ \\
$\begin{array}{l}\text { Characteristics of the cognitive, emotional and behavioural outcomes that individuals believe are } \\
\text { associated with future or intended behaviours and that are either believed to promote or inhibit } \\
\text { these behaviours. These include whether they are sanctions/rewards, proximal/distal, valued/not } \\
\text { valued, probable/improbable, salient/not salient, perceived risks or threats. }\end{array}$
\end{tabular}

Reinforcement Anticipated regret

Consequence

Rewards

Incentives

Punishment

Consequents

Reinforcement

Contingencies

Sanctions
Intentions

Goals and resources

Behaviour regulation

Stability of intentions

Stages of change model

Trans-theoretical model and stages of change

Goals (distal/proximal)

Goal priority

Goal/target setting

Goals (autonomous/ controlled)

Action planning

Implementation intention

Environmental context Environmental stressors

Resources material resources

Organisational culture/climate

Salient events/critical incidents

Person-environment interaction

Barriers and facilitators

Self-monitoring
A sense of the negative consequences of a decision that influences the choice made; for example, an individual may decide not to make an investment because of the feelings associated with an imagined loss.

An outcome of behaviour in a given situation.

Return or recompense, made to or received by a person contingent on some purpose.

An external stimulus, such as a condition or object that enhances or serves as a motive for behaviour.

The process in which a relationship between a response and some stimulus or circumstance results in the response becoming less probable; a painful, unwanted or undesired event or circumstance imposed on a wrong doer.

An outcome of behaviour in a given situation.

A process in which the frequency of a response is increased by a dependent relationship or contingency with a stimulus.

A conditional probabilistic relation between two events. Contingencies may be arranged via dependencies or they emerge by accident.

A punishment or other coercive measure, usually administered by a recognised authority, that is used to penalise and deter inappropriate or unauthorised actions

Ability of one's resolve to remain in spite of disturbing influences.

A model that proposes that behaviour change is accomplished through five specific stages:- precontemplation, contemplation, preparation, action and maintenance.

A five-stage theory to explain changes in people's health behaviour. It suggests that change takes time, that different interventions are effective at different stages, and that there are multiple out comes occurring across different stages.

Desired state of affairs of a person or system; these may be closer (proximal) or further away (distal).

Order of importance or urgency of end states toward which one is striving.

A process that establishes specific time based behaviour targets that are measurable, achievable and realistic.

The end state towards which one is striving: the purpose of an activity or endeavour. It can be observed by observing that a person ceases or changes its behaviour upon attaining this state; proficiency in a task to be achieved within a set period of time.

The action or process of forming a plan regarding a thing to be done or a deed.

The plan that creates in advance of when, where and how one will enact a behaviour.

External factors in the environment that cause stress.

Commodities and human resources used in enacting behaviour.

A distinctive pattern of thought and behaviour shared by members of the same organisation and reflected in their language, values, attitudes, beliefs and customs.

Occurrences that one judges to be distinctive, prominent or otherwise significant.

Interplay between an individual and their surroundings.

In psychological contexts barriers/facilitators are mental, emotional or behavioural limitations/strengths in individuals or groups. 
Table 1 Domains of the Theoretical Domains Framework (TDF) (Continued)

\begin{tabular}{ll}
\hline Domain & Definition \\
\hline & $\begin{array}{l}\text { A method used in behaviour management in which individuals keep a record of their behaviour, } \\
\text { especially in connection with efforts to change or regulate the self; a personality trait reflecting an } \\
\text { ability to modify one's behaviour in response to a situation. }\end{array}$ \\
Breaking habit & $\begin{array}{l}\text { To discontinue a behaviour or sequence of behaviours that is automatically activated by relevant } \\
\text { situational cues. } \\
\text { Tction planning }\end{array}$ \\
\hline
\end{tabular}

non-responders were not recorded separately, and reasons for non-response were not sought.

\section{Data collection}

We combined some TDF domains to reduce the time burden on participants (Additional file 1). The interview schedule contained a mixture of close- and open-ended questions. Conducted by telephone and audio-recorded, interviews lasted 20-60 min. In NZ and Michigan, participants received a $\$ 50$ voucher as a token of appreciation. These interviews were transcribed by a professional transcription service, while a native German speaker residing in NZ transcribed the German interviews and translated them into English. The accuracy of the German-to-English translation was double-checked by another German native speaker against the original audio recording.

\section{Data analysis}

The data were analysed systematically using a deductive approach [26], with the TDF as the framework. The researcher (LS) first read the participant's response and considered it in relation to each TDF domain and its constructs. It would then be attributed to one domain. A sample of the coding across domains was independently coded by a second researcher (SB) to check for accuracy and consistency. If there was disagreement, it was discussed. If agreement could not be reached, the response was coded into both domains. A response not fitting any domain was noted separately (a rare occurrence). The main coder (LS) then highlighted both exemplary quotes for each construct for each country, and any intercountry discrepancies in responses. A simple count of the excerpts grouped under domain constructs and the number of participants per country mentioning those was also undertaken, to provide an overall picture of a domain's pervasiveness without implying validity of the domain or constructs within it. When > 10 participants mentioned a particular construct, it was further broken down into themes.

\section{Results}

Exemplars of comments within each domain are presented. A more detailed description of responses within constructs and domains can be seen by country in Additional file 1.

\section{Knowledge}

Most dentists made comments regarding knowledge, with slightly more relating to procedural than construct knowledge. The former all centred on how the participants treated their patients using NI/MI, with most focusing on NI.

Usually I would look at it first. Afterwards I would use a probe to check whether or not the enamel is still intact. If in doubt I would take a bitewing $x$-ray. If the surface is still intact then I opt for non-invasive measures, regular recalls prophylaxis and fluoride treatment. (G2)

Table 2 Summary of participant demographic characteristics

\begin{tabular}{|c|c|c|c|c|c|}
\hline Country & Sex & $\begin{array}{l}\text { Mean (range) years } \\
\text { of experience* }\end{array}$ & Location of practice & Type of practice & Case mix (reimbursement scheme) \\
\hline USA--Michigan $(n=20)$ & $\begin{array}{l}5 \text { female } \\
15 \text { male }\end{array}$ & $20(1-42)$ & $\begin{array}{l}19 \text { urban } \\
1 \text { rural }\end{array}$ & $\begin{array}{l}12 \text { group } \\
5 \text { sole } \\
3 \text { unknown }\end{array}$ & $\begin{array}{l}6 \text { private only } \\
12 \text { mixed } \\
1 \text { insurer } \\
1 \text { not disclosed }\end{array}$ \\
\hline New Zealand $(n=12)$ & $\begin{array}{l}5 \text { female } \\
7 \text { male }\end{array}$ & $26(6-47)$ & $\begin{array}{l}9 \text { urban } \\
3 \text { rural }\end{array}$ & $\begin{array}{l}9 \text { group } \\
3 \text { sole }\end{array}$ & All fee for service \\
\hline Germany $(n=12)$ & $\begin{array}{l}7 \text { female } \\
5 \text { male }\end{array}$ & $18(1-41)$ & $\begin{array}{l}8 \text { urban } \\
4 \text { rural }\end{array}$ & $\begin{array}{l}9 \text { group } \\
3 \text { sole }\end{array}$ & Predominantly statutory health insurance \\
\hline Total $(n=44)$ & $\begin{array}{l}17 \text { female } \\
27 \text { male }\end{array}$ & $22(1-47)^{*}$ & $\begin{array}{l}36 \text { urban } \\
8 \text { rural }\end{array}$ & $\begin{array}{l}30 \text { group } \\
11 \text { sole } \\
3 \text { unknown }\end{array}$ & \\
\hline
\end{tabular}


Comments grouped under knowledge of the task environment reflected knowledge of their patients' dental/ oral health history and how "compliant" they were perceived to be:

At the enamel dentine junction, I have to think more about what this patient is like... how acidic is their mouth, how compliant are they going to be with the products. If they're not interested in the products at all and they have terrible oral hygiene, then ... we would need to do other things... non-invasive measures are not going to work. (NZ3)

Knowledge construct comments generally linked with knowledge of the scientific literature, etc.

If those new researches/findings remain out there for a few years, then yes. If they are only short-term studies, that have only been around for a year, then I would be very reluctant [to try them]. However, attending advanced courses and reading specialist journals helps to keep up to date. (G9)

A number also mentioned the importance of continuing education and reading dental journals. By contrast, a number said that they based their treatment on what they had learned at dental school. This was mainly the case with the Michigan and German dentists, who also reported that they did not undertake any ongoing education or professional development.

I'd like to learn more about other modalities of treatment as well, more than I know. I don't feel like I've had, because that's not something that was taught when I was at dental school, so ... I feel like I am a little short on knowledge or up-to-date with what the latest scientific recommendations are. (USA6)

\section{Interviewer: Are your recommendations supported by} studies?

I believe so because this is what I was told at university. (G2)

\section{Skills}

Few comments could be grouped under "skills". Some listed fluoride application, but participants also commented on dietary advice, flossing and general oral hygiene. Comments falling under skills related primarily to experience, with many reporting that their clinical knowledge and professional judgement on using NI/MI increased with time in practice.
I mean you don't come out of Dental School having done lots...of things. You have done a few of many things, and so you, the real learning starts, I mean certainly from personal experience in that first year out, where you become exposed to techniques you know, modern and preventive techniques that you might not have even heard of. I came out of Dental School and really it was brush teeth, floss your teeth and we will paint fluoride stuff on, but we have come a long way since then. (NZ8)

A lot of it is your experience you've built up over a period of time and sometimes I'm right and sometimes I could be wrong. So but I follow my best judgement. But it's not a written list in essence. It is the 36 years of experience I have in dealing with the management of caries. (USA18)

\section{Social influences}

All commented under this domain. Most comments fell under the social pressure construct, with patient "compliance" and oral hygiene as pressure factors influencing their decision to use NI/MI. There were 72 mentions of issues related to patient "compliance" (adherence to the dentist's instructions).

Well that is the compliance. If he (patient) is willing to come in for regular recalls, do his homework, meaning proper tooth brushing at home and interdental hygiene. Also to brush his tongue, mucosa of the cheeks and to now and then use antibacterial mouthwash [and] if that isn't the case and the patient does not think it is important to brush his/her teeth, then it can certainly be the case that we will directly do a filling. (G2)

The only factor that would influence us to not offer treatment would be if somebody was really not interested and they didn't show any signs of interest and we consider that it is going to be a waste of time. But you do get some patients or some children that they are not going to do what you ask them and I think that becomes a problem. (NZ10)

Next was financial pressure, mostly from the German (23 mentions), followed by Michigan (18 mentions) and then NZ participants (2 mentions). All Germans mentioned the statutory German insurance and its lack of financial reimbursement for NI/MI. Many of the Michigan dentists mentioned the US public health insurance not covering NI/MI, with this causing them financial stress.

Well you know, unfortunately the financial advantage is kind of a negative because I'm financially advantaged 
to go in and do invasive care, I'm not saying that that's a good thing. (USA8)

Wider professional organisations and participants comparing their practice to that of other dentists were also commonly mentioned (social comparisons). More German (11 from 12) and Michigan participants (17 from 20) compared their practice to other dentists than NZ participants (six from 12).

Well if I do a filling then I will get paid. If I don't do $i t$, and tell the patient, we will observe (the dental situation), then I don't get any money. At least a lot less and yes, that is why one or other colleagues tend to... do a filling, even though one may have easily been able to just observe it. (G2)

Well I think I'm seeing, you know in slow economic times, I think unfortunately we see a lot of these restoration, these lesions restored when they otherwise could've been treated by other means, unfortunately that happens so that's not really a benefit to the patient but more of a benefit to the provider. (USA12)

\section{Social professional role and identity}

Most comments were grouped under the professional role construct, followed by professional identity, while fewer fell under social identity and none under identity. Professional identity comments centred on membership of professional bodies, and being knowledgeable about and adhering to evidence or guidelines. Group identity statements pertained to relationships with dental peers. Most comments categorised under professional boundaries centred on economic factors; that is, not engaging in specific treatments for financial profit.

There are certain colleagues that go by how much they get paid off it, but would probably also do worse fillings. I am sure it is mixed. I don't know this for sure. To be honest I don't really like to talk about how much it costs. (G10)

Comments grouped under professional role were varied, although most covered "educating" patients about good oral health or hygiene practices. Clearly, many participants viewed it as part of their professional role to raise patient awareness of good oral hygiene. It is interesting to note, however, that a few dentists made comments linking carrying out NI measures with hygienists, prophylaxis assistants or nurses.

\section{Beliefs about consequences}

The largest number of comments was grouped under beliefs, followed by outcome expectancies and characteristics of outcome expectancies. The overwhelming majority of comments related to the disadvantages of treating non-cavitated caries lesions with restorations. Almost all of the NZ and German participants and nearly half of the Michigan participants stated that restorations weakened the tooth structure, starting the cycle of restoration replacements. The following were typical.

The advantage is the preservation of the tooth structure. We will preserve the tooth without a filling because even the best filling isn't the greatest compared to an untouched enamel layer. (G2)

I think the biggest benefit is...my belief is that there is nothing better for the tooth than its own natural tooth structure with the filling in place once it is... we know that it has got a certain life expectancy that eventually that filling is going to break down and a bigger filling has to be placed and then a crown has to be placed and it is starting that process for more damage to the tooth. (USA1)

Many dentists saw NI/MI as a way of avoiding restoring non-cavitated proximal lesions. A number also reported that these methods could lead to remineralisation or lesion arrest.

I have a lot of lesions that are in enamel only that I see that my colleagues would just treat immediately and I think that there's potential for remineralisation with getting people better in their hygiene and their diet and trying to reduce the acid injury to the enamel there, and I think there's a chance for natural remineralisation if the acid injury is arrested, slowed down anyway by different factors like fluoride and hygiene and dietary regulation. (G9)

At the same time, however, a large number of comments were grouped under anticipated regret (11 NZ, 9 German, 5 USA), that is, not being able to arrest lesions via NI/MI when still small and seeing them progress subsequently to requiring larger restorations. This was often associated with comments related to patients' poor oral health attitudes and/or "noncompliance".

Sometimes you will see a cavity and it is small and you think, oh I should drill that and then you second guess yourself and say, you shouldn't. Then two years later they are back again and you think, oh thank goodness, I didn't drill that and other times there is a massive cavity there and you bitterly regret your decision. (NZ1) 


\section{Reinforcement}

Most comments here were grouped under incentives, followed by rewards and reinforcement. Interestingly, very few (but all from Michigan) were grouped under sanctions, punishment and contingencies. As incentives, the benefits of non-invasive measures-such as remineralisation, not destroying tooth structure-were mentioned. As rewards, professional satisfaction and peace of mind were identified, along with enhanced dentist-patient relationships. Some Michigan dentists made comments that suggested they achieved professional satisfaction from treating patients with NI/MI. A few also listed having more patients as a benefit of using NI/MI, and four mentioned enhanced relationships with patients.

Because one will end up having more satisfied patients and a better bond with the patients. Patients are also a multiplication factor, [as] they recommend [me] to others and then I will have more satisfied patients in the practice... work is a lot more fun that way. (G5)

I mean in terms of benefits I guess it's fulfilling...as a career can be in that I honestly feel as though I'm helping people be truly healthy. I think and the staff feels that, so that would be the main benefit there in terms of being fulfilled in regards to our careers. (USA7)

\section{Intentions}

Only a few comments were associated with intentions (all under stability of intentions). These generally centred on the desire to use NI/MI whenever possible. Most stated that they would use NI in the outer half of the enamel, but fewer would if a caries lesion had reached the dentin-enamel junction. Most would alter their management strategy if patients had poor oral hygiene or if they felt patients would not follow their hygiene instructions.

Yes, definitely a priority for us in our practice. I do feel that, the less you do to the tooth the better chance that you have surviving longer, because as soon as you drill the tooth, really every couple of years you need to replace that filling. Every time you take a drill to a tooth, even if you try and be minimally invasive you will always make a bigger hole when you go back in. The best thing is not to start. (NZ6)

\section{Goals}

Approximately half of the NZ dentists made a comment that was grouped under one or more of the six constructs associated with goals, while fewer of the German and Michigan dentists made such statements. There was a marked overlap between the goals and intention domains, with an example of action planning being.

... the decision ultimately is the patient's and what they'd like to do. I merely just give them information and recommendations, and you know more often than not they defer to the practitioner anyway. Ah but I do feel you know an obligation to help these patients be as healthy as they can and in my opinion being minimally invasive, or being conservative, you know preserving their natural tooth as long as possible without negative outcomes is important. (USA7)

\section{Environmental context and resources}

Environmental context and resources comprised one of the larger domains for responses. Most comments were grouped under resources and material resources, followed by environmental stressors and organisational culture/climate. Comments categorised under resources/ material resources generally centred not only on the lack of financial reimbursement for NI/MI but also on regulatory restrictions.

There's... a lot more advantages for the dentist to cut a filling 'cos you, you get one...you get the fee for doing the filling and then two, eventually you get up to get the fee for replacing that filling at some time in the future. And then maybe 20 years down the track you end up having to do a larger restoration or a crown when the cusp cracks (NZ4)

It isn't paid. It requires more work that is not paid. Hence it isn't really worth it for me. Maybe for the patient but sadly not for me. It just isn't paid well. (G4)

Comments under organisational culture and climate pertained to colleagues supporting the use of NI/MI, or vice versa, with the organisational culture/climate being unsupportive.

My hygienists are very preventive orientated you know and they've kind of encouraged the adoption of the fluoride varnish and... so I guess that was an enabler for me that my staff was gung ho. (USA5)

Comments under enablers mentioned specific technologies (such as digital radiographs, magnification).

Digital $x$-rays and being able to show people $x$-rays that they can see without having to look through a magnifying glasses and things, that makes it very real for people. So having sharp clear $x$-rays um, that are 
life size or bigger than life size that patients can see clearly and you can demonstrate progress and show them also. That, is the biggest educational tool 'cos we're living in a digital age where seeing is believing. (NZ4)

Some Michigan participants also mentioned that instructing patients on NI was time-consuming, with patients reluctant to attend the required multiple appointments; in addition, NI/MI were good for patients with low pain thresholds or who were anxious.

\section{Behaviour regulation}

Behaviour regulation was the domain with fewest responses, possibly because most participants were already using NI/MI. One example, however, of how participants were motivating others was as follows.

So in our practice ... we've set about just recently on actually rewarding each other within the practice using a card reward system where if you see another member of our team not doing standard brush and floss-type stuff but actually tailoring the message to that individual patient um with something that's much more achievable. (USA13)

\section{Barriers and enablers across different countries}

Six barriers were identified. One of the most commonly mentioned included a lack of (or less) remuneration for NI/MI under different dental health funding schemes.

National health insurance does not pay for non- or micro-invasive measures. There is no real financial support for it and...that's why, speaking from an economical perspective, support (from the national health insurance) will only happen once we start using the drill. (G3)

Unfortunately the financial advantage is kind of negative because I'm financially advantaged to go in and do invasive... care, I'm not saying that that's a good thing but when you look at it strictly like that. (USA7)

Time pressure to perform NI/MI procedures was also mentioned as a common barrier, more likely to be mentioned by the German and US participants.

The disadvantage is that minimal invasive treatments require more time, compared to those that are not minimal invasive. (G8)

So I guess sometimes the barrier can be time if a patient needs extra time and educating. (USA4)
Not undertaking continuing professional development and basing treatment on their initial dental training was a further barrier, but identified only in the German and US participants' responses.

I really can't tell you. I haven't looked at any studies for 20 years. (G1)

The dental education when I was in Dental School. (USA11)

A sense of anticipated regret (anxiety about not restoring an early proximal lesion before it progressed) was another barrier.

Dentists' beliefs about whether patients were likely to adhere to oral hygiene instructions in the future and whether they were high-caries risk-as well as having unsupportive colleagues and/or practice leaders who were not interested in such methods-were two further barriers. Although most said their colleagues supported NI/MI management, there were exceptions. In some cases, these unsupportive colleagues were in a higher status position.

So [name] is in his late sixties now. I think it would be fair to say and think he'd probably agree that he can't be bothered with [preventive measures] anymore. (NZ5)

A similar number of enablers were identified; one was the belief that remineralisation can occur in non-cavitated proximal lesions and that those can be arrested.

It's all about seeing evidence of arrested lesions, evidence of decalcification that has remineralised in people whether it's radiographic or pictorial evidence, it might require both, but you've got a widely held and standard procedure dentistry for decades that a lesion that has not penetrated DEJ can remineralise and stay that way for 75 or 100 years if its properly cared for. (USA2)

The understanding that restorations serve to weaken tooth structure was also a second identified enabler.

Directly to avoid having restorative work done on their teeth and preserving the natural tooth structure because it's widely accepted that once a restoration is placed in the tooth...it's going to lead to a lifetime of more restorations, they're going to get larger and larger and maintaining... existing tooth structure should be of paramount priority. (G2)

Undertaking ongoing professional development and continuing education (and maintaining membership in professional groups) was another enabler. 
The dentists that I meet up with at advanced training/ education courses and attend advanced training/ education courses together or that I meet there are all, working [on] the same concept [incorporating NI/MI] as myself. However, we are not representing all the dentists. Sadly this is how it is. (G5)

Having supportive practice colleagues and skilled dental team members who work collaboratively to undertake non-invasive procedures (such as cleaning and scaling) was another enabler. Some mentioned the significant role of dental hygienists, prophylaxis assistants or dental nurses in undertaking NI/MI methods, as well as alerting dentists and patients when they had non-cavitated lesions that needed monitoring.

What we normally do is, oral hygiene instruction with flossing keeping the area clean, this is usually reinforced by the hygienists as well and also a fluoride application. (NZ6)

My hygienists are very preventive orientated you know and they've kind of encouraged the adoption of the fluoride varnish and... so I guess that was an enabler for me that my staff was gung ho. (USA5)

Having the necessary finances, equipment and staff resources was also identified as an enabler.

I think ... digital $x$-rays and being able to show people $x$-rays that they can see without having to look through a magnifying glasses and things, that makes it very real for people. ... and also just the immediacy of a digital $x$-ray, which pops up on the screen and having good, clear $x$-rays. Not sort of spotty, murky, fuzzy ones. So having sharp clear $x$-rays ... that are life size or bigger than life size that patients can see clearly and you can demonstrate progress and show them also. That, is the biggest educational tool 'cos we're living in a digital age where seeing is believing. (NZ4)

There were similarities and differences across countries (Table 3). The lack of remuneration or time was mentioned by nearly all; insurance systems (public or private) restrict remuneration for NI/MI to children or adolescents, with higher remuneration for restorations. The US dentists, notably, mentioned that placing restorations early on would enhance their survival chances, which is relevant given that dentists guarantee survival for some time (the same regulation is in place in Germany).

Anticipated regret was also a general theme, manifested in the fear of not having managed lesions early by placing a restoration. The hope of changing patients' risk profile seems limited, especially among the German and US dentists. For many, placing restorations is the "safer" option.

Relying on knowledge from dental school was more commonly found in Germany: nearly half of the German dentists mentioned that their treatment philosophy generally reflected what they learnt at university. By contrast, undertaking professional development or belonging to professional educational groups or having discussions with peers was more common with the NZ and US dentists, with only a few German dentists mentioning it. Having colleagues who supported NI/MI was another enabler, mainly among the NZ and US dentists.

Having the goal or priority of performing NI/MI was also a relevant enabler, mentioned by most NZ dentists, but only a few German and US dentists. Those who mentioned it all intimated that they wanted to do the right thing for their patients and felt good when it succeeded.

\section{Discussion}

Two major groups of factors influenced dentists' behaviour. The first was associated with knowledge, skills and the theoretical understanding of how to best manage dental caries and caries lesions. An awareness of the scientific literature-of the benefits of implementing NI/ MI, and what these methods involve-was an enabler [7, 27]. Moreover, the experience that remineralisation can occur in non-cavitated lesions with fluoride application and dietary changes positively affects attitudes towards NI/MI $[28,29]$. Having positive experiences and knowing about the research data could help to alleviate the fear that non-restored lesions could progress. This is relevant because many dentists (especially the US and German dentists) found restorations to be the "safer" treatment option, despite usually being aware of the long-term problems arising from restoration placement. This contradiction was even more strikingly for highrisk patients, where restorations have especially poor outcomes [16], while MI treatments have been especially successful here [7]. Another relevant aspect was the patient as a possible risk factor to be considered. Poor "compliance" and unmanageably high-caries risk were commonly cited reasons for not using NI/MI. Many dentists felt somewhat unable to reliably manage patients' behaviour. This was more pertinent in Germany and the USA, while NZ dentists were generally more optimistic that they could do it.

The social aspects also shape behaviour, which may impact within the practice or the wider healthcare setting. For example, mandating guarantee times on restorations incentivised restorative overtreatment, shifting priorities towards restoration longevity, not patients' health or tooth retention [21, 30, 31]. Another important barrier was NI/MI being remunerated only for children or adolescents [15, 32]. Such a restriction goes against 


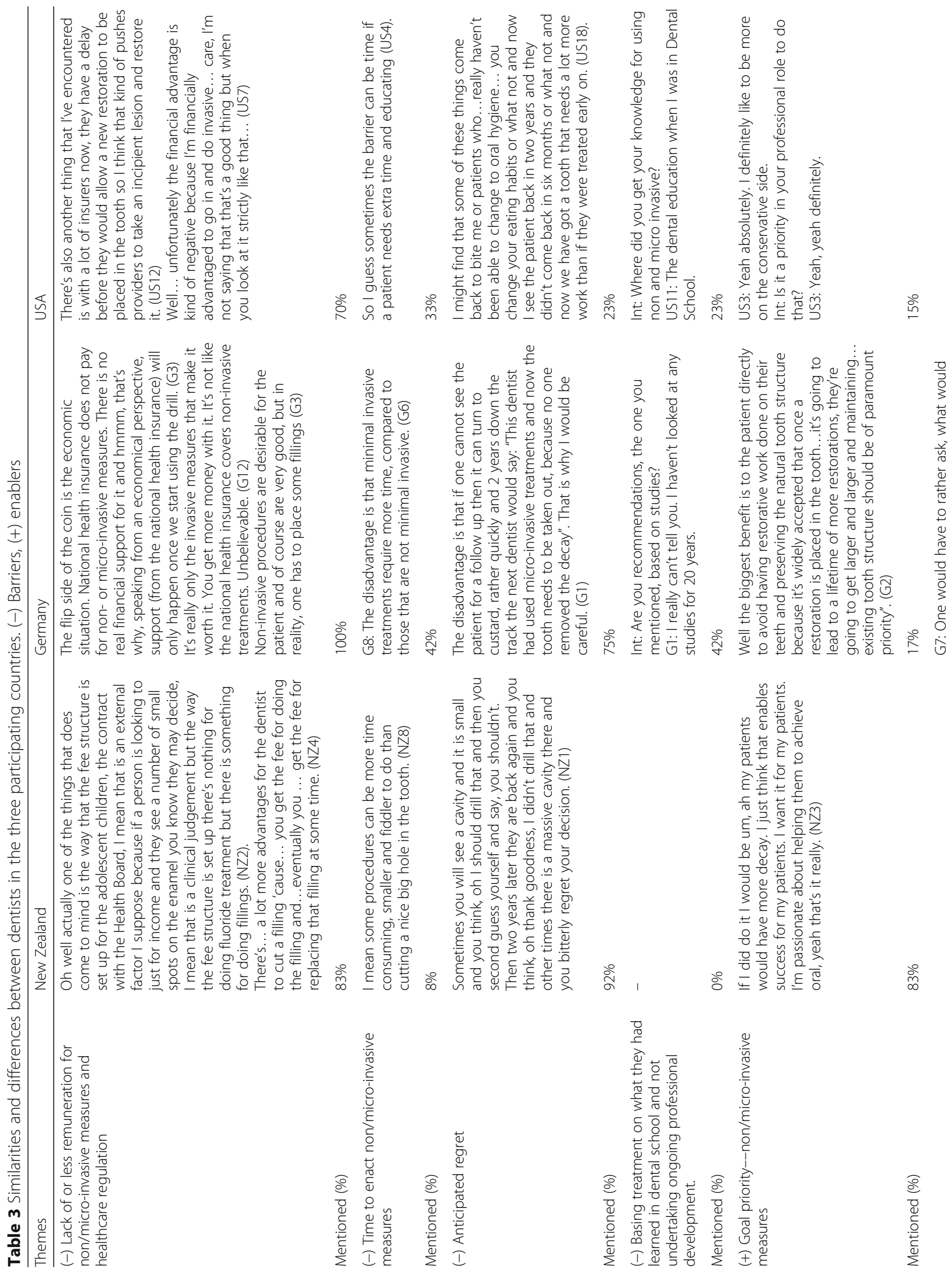




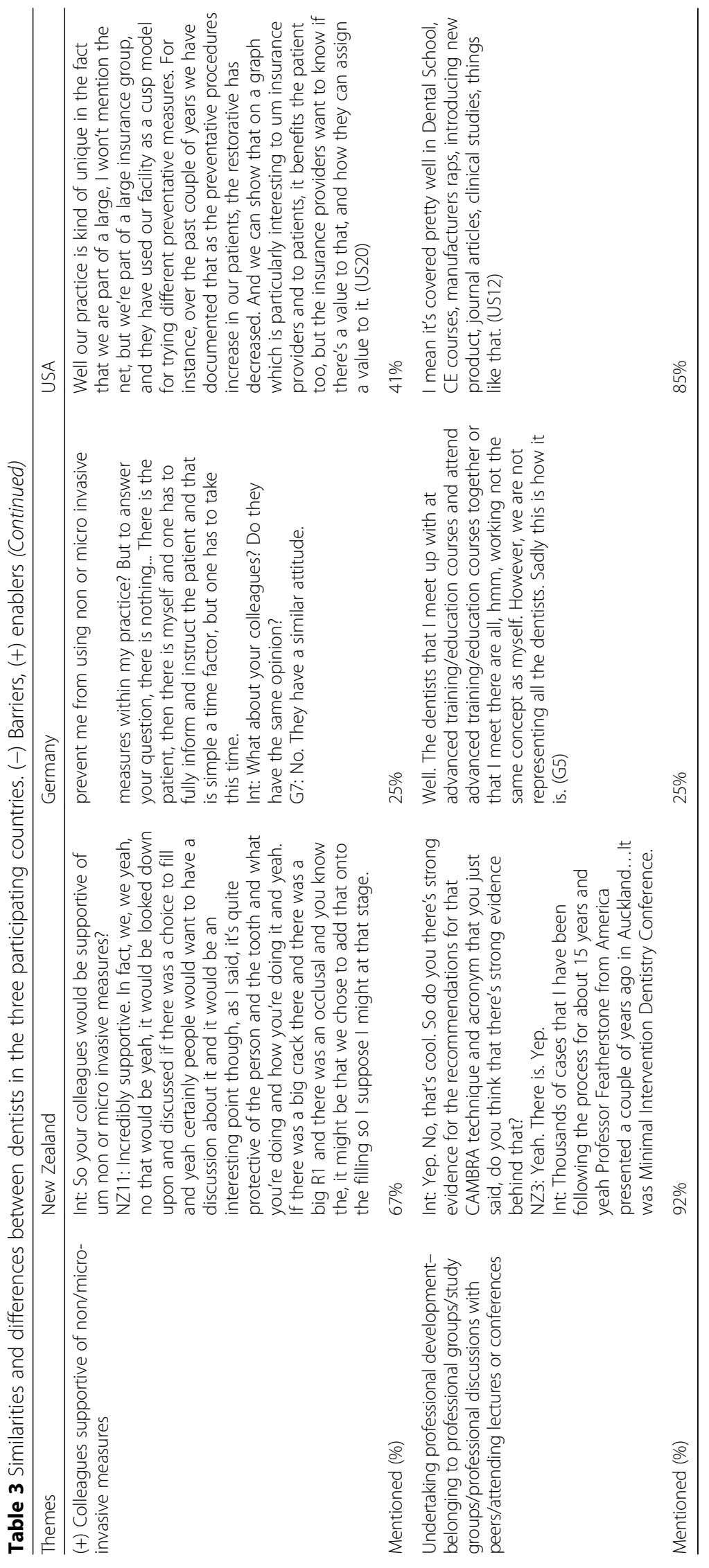


long-term cohort data showing that the caries increment (number of surfaces newly affected/year) remains largely constant through life; caries is not just a disease of childhood or adolescence [33]. Moreover, all three dental healthcare systems appeared to pay better for restorative interventions than for NI/MI. Hence, dentists felt unable to provide NI/MI in some cases because this would not cover their expenses. Delegation of NI/MI procedures to auxiliary staff could improve NI/MI profitability in dental practice: the cost-effectiveness of NI/MI is very high in school or other non-practice settings [34]. Indeed, sharing responsibilities among the dental team has generally been found to enable less invasive caries management [15, 35].

We identified a number of aspects to be targeted by interventions to help close the implementation gap. First, dentists should be encouraged to regularly undertake continuous professional development (CPD), particularly in cariology [35]. Second, pre- and postgraduate education should focus more on dentists being not only just skilled treatment providers but also effective patient communicators $[15,35,36]$. If dentists could communicate effectively with patients about preventive techniques and behaviour change, the risk of anticipated regret and the associated wish to over-treat to be "safe" might decrease over time. Third, remuneration and regulatory practices should be aligned with current evidence. Outdated financial incentives favouring restorative or even prosthetic care will perpetuate outdated and (in some cases) harmful treatment approaches. Instead, remuneration and regulation should have appropriate incentives. Finally, there is a need for tools to easily, repeatedly and validly record and monitor early lesions. Since radiography has limitations and also requires high standardisation and the use of ionising radiation, technologies such as light transillumination may become more useful [37].

This study has a number of strengths and limitations. A large and diverse range of dentists from different countries was interviewed, allowing exploration of "drivers to practice" among countries and understanding setting-specific factors. The TDF provided the underpinning theoretical structure; while such a framework is advantageous [32], its use may have had unintended consequences (for example, findings are over-determined and/or alternative interpretations are left unconsidered) [32]. For instance, some comments were grouped into more than one domain, which may have resulted in more focus being placed on those than was warranted. To date, no studies have examined the fidelity of TDF application or those unintended consequences. Moreover, this was a qualitative study using interviews; future studies should aim to triangulate findings using other approaches. This would be in line with recent calls for triangulation of data using the TDF from questionnaires, interviews and observation [26].

\section{Conclusions}

The decision on how to manage non-cavitated proximal lesions was influenced by numerous factors, and these differed to a certain extent among the three countries. As barriers to NI/MI, we identified lack of time or remuneration, basing treatment decisions on knowledge that is out of date, and a lack of patient "compliance" and involvement in decision-making. Enablers were undertaking ongoing professional development, being part of a professional group and working in a supportive environment. Financial reimbursement systems should fund NI/ MI so that its clinical uptake is enhanced. Licencing bodies should insist on appropriate professional development in cariology or preventive dentistry as part of dentists' ongoing registration. Undergraduate dental education programmes and CPD courses are the key to instilling shared decision-making principles as a cornerstone of the dental consultation.

\section{Additional file}

Additional file 1: Interview guides and examples of comments grouped under the different domains and constructs. (DOCX $46 \mathrm{~kb}$ )

\section{Acknowledgements}

We thank the DMG, Hamburg, for funding this study and express our gratitude to the participants. We also thank John Girwood, University of Michigan, for interviewing the US participants.

\section{Funding}

This study was funded by the DMG, Hamburg. The funders had no role in planning, conducting or analysing the study and the data.

\section{Availability of data and materials}

The datasets used and/or analysed during the current study are available from the corresponding author on reasonable request.

\section{Authors' contributions}

FS conceived and designed the study, co-developed the interview schedule, interpreted the data and wrote and agreed to the manuscript. LFP conceived and designed the study, co-developed the interview schedule, interpreted the data and revised and agreed to the manuscript. LAS co-developed the interview schedule, analysed and interpreted the data, and revised and agreed to the manuscript. MF conceived and designed the study, co-developed the interview schedule, interpreted the data and revised and agreed to the manuscript. WMT co-developed the interview schedule, interpreted the data and revised and agreed to the manuscript. SRB conceived and designed the study, developed the interview schedule, interpreted the data and revised and agreed to the manuscript. All authors read and approved the final manuscript.

\section{Ethics approval and consent to participate}

All participants gave their consent and permission to participate in this study. The ethics committees of all three participating universities agreed to this study (Charité - Universitätsmedizin Berlin EA2/137/14, University of Otago D16/276, University of Michigan HUM00120913).

Consent for publication Not applicable.

\section{Competing interests}

The authors have received funding for this study by the DMG, Hamburg. The authors also acknowledge to have performed clinical or pre-clinical data funded or supported by the DMG, Hamburg. Some authors also received support for lectures by the DMG, Hamburg. 


\section{Publisher's Note}

Springer Nature remains neutral with regard to jurisdictional claims in published maps and institutional affiliations.

\begin{abstract}
Author details
'Department for Operative and Preventive Dentistry, Charité Universitätsmedizin Berlin, Freie Universität Berlin, Humboldt-Universität zu Berlin, and Berlin Institute of Health, Aßmannshauser Str. 4-6, 14197 Berlin, Germany. ${ }^{2}$ Department of Oral Sciences, Faculty of Dentistry, University of Otago, Dunedin, New Zealand. ${ }^{3}$ Department of Cariology, Restorative Sciences and Endodontics, School of Dentistry, University of Michigan, Ann Arbor, USA. ${ }^{4}$ Unit of Oral Health, Dentistry and Society, School of Clinical Dentistry, University of Sheffield, Sheffield, UK.
\end{abstract}

\section{Received: 10 October 2017 Accepted: 26 March 2018} Published online: 06 April 2018

\section{References}

1. Listl S, Galloway J, Mossey PA, Marcenes W. Global economic impact of dental diseases. J Dent Res. 2015;94(10):1355-61.

2. Kassebaum NJ, Bernabe E, Dahiya M, Bhandari B, Murray CJ, Marcenes W. Global burden of untreated caries: a systematic review and metaregression. J Dent Res. 2015;94(5):650-8.

3. Marsh PD. Dental plaque as a biofilm and a microbial community-implications for health and disease. BMC Oral Health. 2006;6(S1):S14.

4. Schwendicke F, Jäger AM, Paris S, Hsu L-Y, Tu Y-K. Treating pit-and-fissure caries: a systematic review and network meta-analysis. J Dent Res. 2015; 94(4):522-33.

5. Paris S, Ekstrand K, Meyer-Lückel H. Von der Diagnose zu Therapie. In: Paris S, Ekstrand K, Meyer-Lückel H, editors. Karies, Wissenschaft und klinische Praxis. Stuttgart: Thieme; 2012.

6. Schwendicke F, Frencken JE, Bjorndal L, Maltz M, Manton DJ, Ricketts D, Van Landuyt K, Banerjee A, Campus G, Domejean S, et al. Managing carious lesions: consensus recommendations on carious tissue removal. Adv Dent Res. 2016;28(2):58-67.

7. Dorri M, Dunn S, Sabbah W, Schwendicke F. Micro-invasive interventions for managing proximal dental decay in primary and permanent teeth. Cochrane Database Syst Rev. 2015;11:CD010431.

8. Schwendicke F, Meyer-Lueckel H, Stolpe M, Dorfer CE, Paris S. Costs and effectiveness of treatment alternatives for proximal caries lesions. PLoS One. 2014;9(1):e86992

9. Brantley C, Bader J, Shugars D, Nesbit S. Does the cycle of rerestoration lead to larger restorations? J Am Dent Assoc. 1995;126(10):1407-13.

10. Schwendicke F, Gostemeyer G, Blunck U, Paris S, Hsu LY, Tu YK. Directly placed restorative materials: review and network meta-analysis. J Dent Res. 2016:95(6):613-22

11. Innes N, Schwendicke F. Dentists' thresholds for restorative intervention in carious lesions: systematic review and meta-analysis. J Dent Res. 2017:96(5):501-8.

12. Domejean-Orliaguet S, Leger S, Auclair C, Gerbaud L, Tubert-Jeannin S. Caries management decision: influence of dentist and patient factors in the provision of dental services. J Dent. 2009;37(11):827-34.

13. Kakudate N, Sumida F, Matsumoto Y, Manabe K, Yokoyama Y, Gilbert GH, Gordan W. Restorative treatment thresholds for proximal caries in dental PBRN. J Dent Res. 2012;91(12):1202-8.

14. Tan PL, Evans RW, Morgan MV. Caries, bitewings, and treatment decisions. Aust Dent J. 2002;47(2):138-41. quiz 182

15. Sbaraini A, Carter SM, Evans RW, Blinkhorn A. How do dentists and their teams incorporate evidence about preventive care? An empirical study. Community Dent Oral Epidemiol. 2013;41(5):401-14.

16. Demarco FF, Correa MB, Cenci MS, Moraes RR, Opdam NJ. Longevity of posterior composite restorations: not only a matter of materials. Dent Mater. 2012;28(1):87-101.

17. Gnich W, Bonetti D, Sherriff A, Sharma S, Conway DI, Macpherson LMD. Use of the theoretical domains framework to further understanding of what influences application of fluoride varnish to children's teeth: a national survey of general dental practitioners in Scotland. Community Dent Oral Epidemiol. 2015;43(3):272-81

18. Templeton AR, Young L, Bish A, Gnich W, Cassie H, Treweek S, Bonetti D, Stirling D, Macpherson L, McCann S, et al. Patient-, organization-, and systemlevel barriers and facilitators to preventive oral health care: a convergent mixed-methods study in primary dental care. Implement Sci. 2016;11:5.
19. Michie S, Pilling S, Garety P, Whitty P, Eccles MP, Johnston M, Simmons J. Difficulties implementing a mental health guideline: an exploratory investigation using psychological theory. Implement Sci. 2007;2:8.

20. French SD, Green SE, O'Connor DA, McKenzie JE, Francis JJ, Michie S, Buchbinder R, Schattner P, Spike N, Grimshaw JM. Developing theoryinformed behaviour change interventions to implement evidence into practice: a systematic approach using the Theoretical Domains Framework. Implement Sci. 2012;7:38

21. Schwendicke F, Gostemeyer G. Understanding dentists' management of deep carious lesions in permanent teeth: a systematic review and metaanalysis. Implement Sci. 2016;11(1):142.

22. Tong A, Sainsbury P, Craig J. Consolidated criteria for reporting qualitative research (COREQ): a 32-item checklist for interviews and focus groups. Int J Qual Health Care. 2007;19(6):349-57.

23. Cane J, O'Connor D, Michie S. Validation of the theoretical domains framework for use in behaviour change and implementation research. Implement Sci. 2012;7:37.

24. Dworkin SL. Sample size policy for qualitative studies using in-depth interviews. Arch Sex Behav. 2012;41(6):1319-20.

25. O'Reilly M, Parker N. 'Unsatisfactory saturation': a critical exploration of the notion of saturated sample sizes in qualitative research. Qual Res. 2012;13(2):190-7.

26. Atkins $L$, Francis J, Islam R, O'Connor D, Patey A, Ivers N, Foy R, Duncan EM, Colquhoun $\mathrm{H}$, Grimshaw JM, et al. A guide to using the Theoretical Domains Framework of behaviour change to investigate implementation problems. Implement Sci. 2017;12(1):77.

27. Splieth $\mathrm{CH}$, Ekstrand KR, Alkilzy M, Clarkson J, Meyer-Lueckel H, Martignon S, Paris S, Pitts NB, Ricketts DN, van Loveren C. Sealants in dentistry: outcomes of the ORCA Saturday Afternoon Symposium 2007. Caries Res. 2010;44(1):3-13.

28. Marinho VC, Worthington HV, Walsh T, Clarkson JE. Fluoride varnishes for preventing dental caries in children and adolescents. Cochrane Database Syst Rev. 2013;7:Cd002279.

29. Harris R, Gamboa A, Dailey Y, Ashcroft A. One-to-one dietary interventions undertaken in a dental setting to change dietary behaviour. Cochrane Database Syst Rev. 2012;3:Cd006540.

30. Schwendicke F, Meyer-Lueckel H, Dorfer C, Paris S. Attitudes and behaviour regarding deep dentin caries removal: a survey among German dentists. Caries Res. 2013:47(6):566-73.

31. Schwendicke F, Stangvaltaite L, Holmgren C, Maltz M, Finet M, Elhennawy K, Eriksen I, Kuzmiszyn TC, Kerosuo E, Domejean S. Dentists' attitudes and behaviour regarding deep carious lesion management: a multi-national survey. Clin Oral Investig. 2016;21(1):191-8.

32. Bonetti D, Johnston M, Clarkson JE, Grimshaw J, Pitts NB, Eccles M, Steen N, Thomas R, Maclennan G, Glidewell L, et al. Applying psychological theories to evidence-based clinical practice: identifying factors predictive of placing preventive fissure sealants. Implement Sci. 2010;5:25.

33. Broadbent JM, Foster Page LA, Thomson WM, Poulton R. Permanent dentition caries through the first half of life. Br Dent J. 2013;215(7):E12.

34. Schwendicke F, Splieth CH, Thomson W, Reda S, Stolpe M, Foster Page LA. Cost-effectiveness of caries-preventive fluoride varnish applications in clinic settings among patients of low, moderate, and high risk. Community Dent Oral Epidemiol. 2018;46(1):8-16

35. Suga US, Terada RS, Ubaldini AL, Fujimaki M, Pascotto RC, Batilana AP, Pietrobon R, Vissoci JR, Rodrigues CG. Factors that drive dentists towards or away from dental caries preventive measures: systematic review and metasummary. PLoS One. 2014;9(10):e107831.

36. Watt R, McGlone P, Evans D, Boulton S, Jacobs J, Graham S, Appleton T, Perry S, Sheiham A. The facilitating factors and barriers influencing change in dental practice in a sample of English general dental practitioners. $\mathrm{Br}$ Dent J. 2004:197(8):485-9. discussion 475

37. Kuhnisch J, Sochtig F, Pitchika V, Laubender R, Neuhaus KW, Lussi A, Hickel $R$. In vivo validation of near-infrared light transillumination for interproximal dentin caries detection. Clin Oral Investig. 2016;20(4):821-9. 